\title{
The syllable-based word length effect and stimulus set specificity
}

\author{
TAMRA J. BIRETA, IAN NEATH, and AIMÉE M. SURPRENANT \\ Purdue University, West Lafayette, Indiana
}

\begin{abstract}
The word length effect is the finding that a list of items that take less time to pronounce is better recalled on an immediate serial recall test than an otherwise equivalent list of items that take more time to pronounce. Contrary to the predictions of all major models of the word length effect, Hulme, Suprenant, Bireta, Stuart, and Neath (2004) found that short and long items presented within the same list were recalled equally as well as short items presented in lists of just short items. Different results were reported by Cowan, Baddeley, Elliot, and Norris (2003), who found that mixed lists were recalled worse than pure short lists, but better than pure long lists. The experiments reported here suggest that the different empirical findings are due to properties of the stimulus sets used: one stimulus set produces results that replicate Cowan et al., whereas all other sets tested so far yield results that replicate Hulme et al.
\end{abstract}

The word length effect, the finding that a list of items that takes less time to pronounce is better recalled on an immediate serial recall test than an otherwise equivalent list of items that takes more time to pronounce (Baddeley, Thomson, \& Buchanan, 1975), has featured prominently in recent attempts to test between competing theoretical accounts of immediate memory (e.g., Cowan, Baddeley, Elliot, \& Norris, 2003; Hulme, Surprenant, Bireta, Stuart, $\&$ Neath, 2004). Although the predictions of the models are clear, the data are equivocal. The purpose of the present work is to examine possible reasons for the varied empirical findings.

There are currently at least four different simulation models of the word length effect: the phonological loop hypothesis (Burgess \& Hitch, 1999; Page \& Norris, 1998), the Brown and Hulme (1995) model, the feature model (Neath \& Nairne, 1995), and SIMPLE (Hulme et al., 2004). All predict that immediate serial recall of lists containing words with more syllables will be worse than recall of otherwise comparable lists of words with fewer syllables. However, the four accounts differ in their predictions concerning lists that contain both short and long items. We postpone consideration of SIMPLE's account until the General Discussion, because this model was designed specifically to account for the data on which we focus.

According to the phonological loop hypothesis of working memory, "memory traces decay over a period of a few

Experiments 1 and 2 were part of the first author's master's thesis. We thank James S. Nairne for his extremely useful comments and suggestions. Part of this work was completed while two of the authors (I.N. and A.M.S.) were Visiting Professors at the Department of Psychology, City University, London. T.J.B. is now at The College of New Jersey. I.N. and A.M.S. are now at Memorial University of Newfoundland. Correspondence may be addressed to T. J. Bireta, Psychology Department, The College of New Jersey, P.O. Box 7718, Ewing, NJ 08628 (e-mail: tbireta@tcni.edu) or to I. Neath, Department of Psychology, Memorial University of Newfoundland, St. John's, NL, A1B 3X9 Canada (e-mail: ineath@mun.ca). seconds, unless revived by articulatory rehearsal" (Baddeley, 2000, p. 419). Recall of items in situations thought to depend on the phonological loop is a joint function of the decay rate of the items and the time needed to rehearse them. Given the assumption that there is a positive correlation between the rate of subvocal rehearsal and overt pronunciation time, phonological loop models predict worse recall of lists of items that take longer to pronounce than lists of items that take less time to pronounce. This view, then, predicts that (1) recall of short and long items from mixed lists will be intermediate between recall of short and long items from pure lists and (2) no word length effect will be observed in mixed lists (see, e.g., the simulation results presented in Figure 16 of Burgess \& Hitch, 1999). The reason for the latter prediction is that the amount of time that each item has to be retained is, on average, the same.

The Brown and Hulme (1995) model makes quite different predictions. In this model, the word length effect arises because of differential decay rates for short and long items. Because items decay at their given rate regardless of list composition, this account predicts that recall of short items will be identical whether they constitute a pure list or whether they are mixed with long items. This view, then, predicts that (1) recall of items from mixed lists will be equivalent to recall of the same type of item from pure lists and (2) a word length effect will be observed in mixed lists.

The feature model (Neath \& Nairne, 1995) is similar to the Brown and Hulme (1995) model in that both posit a primarily local origin for the cause of word length effects. In the feature model, long items are assumed to have more segments than short items do. At some point during the retrieval process, the segments need to be assembled. If one assumes a fixed probability of making an error in assembling segments, then more errors will occur for long items than for short items. This view, then, predicts that (1) recall of items from mixed lists will be equivalent to 
recall of the same type of item from pure lists and (2) a word length effect will be observed in mixed lists.

Given the clear predictions - all of them simulationswhich theoretical account is supported by the data? The answer depends on which of two sets of data one examines.

Cowan et al. (2003) reported one experiment in which they examined recall of six-item lists of short (onesyllable) and long (five-syllable) words. There were seven types of list: a list could have no long words (i.e., a pure short list), or it could have one, two, three, four, or five long words (and five, four, three, two, or one short words), or it could have only long words (i.e., a pure long list). Of most interest is the condition with three short and three long words; in the other lists, one would expect an advantage to accrue to the least common type of item as it becomes even less common. Their results are shown in the top row of Table 1: (1) Recall of short and long items from mixed lists is below recall of short items from pure lists (predicted by the phonological loop hypothesis), but (2) short words from mixed lists were recalled better than long words from mixed lists (predicted by the Brown and Hulme model and the feature model).

Hulme et al. (2004) reported two similar experiments that obtained quite different results. Their first experiment had two types of lists: pure (only one-syllable words or only five-syllable words) and alternating (either short long short long short long or long short long short long short). Their second experiment used a different set of stimuli and a different test method, and added a third type of list in which the probability of having a short or long item was randomly determined for each position. Both experiments produced the same pattern of results, shown in the second and third rows of Table 1: (1) Recall of short and long items in mixed lists is equivalent to recall of short items from pure lists (predicted by no account), and (2) there is no word length effect in mixed lists (predicted by the phonological loop hypothesis).

The purpose of the experiments reported here was to determine the cause of the difference. The two most obvious differences between the Cowan et al. (2003) and Hulme et al. (2004) studies were (1) the particular stimuli used and (2) the type of mixed list. Experiment 1 was designed as a replication of Cowan et al., using both their stimuli and their mixed lists. Experiment 2 was designed as a partial replication of Experiment 2 of Hulme et al. using their stimuli but Cowan's mixed lists. Experiment 3 used Cowan's stimuli and Hulme's mixed lists, and Experiment 4 used a new set of stimuli and Cowan's mixed lists.

\section{EXPERIMENT 1}

Experiment 1 was designed to replicate Cowan et al. (2003).

\section{Method}

Subjects. Twenty Purdue University undergraduates participated in exchange for credit in introductory psychology courses. All identified themselves as native speakers of American English.

Stimuli. The stimuli were the six short words (birch, clam, hoof, myth, pest, trait) and six long words (administration, criminology, enthusiasm, hypochondriac, photosynthesis, undergraduate) used by Cowan et al. (2003).

Design. The design was almost identical to that used by Cowan et al. (2003), except that we did not include a concurrent articula-

Table 1

Proportions of Short and Long Words Recalled Correctly, and Standard Errors of the Means, As a Function of List Type

\begin{tabular}{|c|c|c|c|c|c|c|c|c|c|c|c|c|c|}
\hline \multirow[b]{3}{*}{ Source } & \multicolumn{11}{|c|}{ Number of Long Words in Mixed Lists } & & \\
\hline & & \multicolumn{2}{|c|}{1} & \multicolumn{2}{|c|}{2} & \multicolumn{2}{|c|}{3} & \multicolumn{2}{|c|}{4} & \multicolumn{2}{|c|}{5} & \multicolumn{2}{|c|}{ Pure Lists } \\
\hline & & $M$ & $S E$ & $M$ & $S E$ & $M$ & $S E$ & $M$ & $S E$ & $M$ & $S E$ & $M$ & $S E$ \\
\hline \multirow[t]{3}{*}{ Cowan et al. (2003) } & Short & 0.58 & 0.03 & 0.54 & 0.03 & 0.58 & 0.03 & 0.54 & 0.04 & 0.61 & 0.04 & 0.61 & 0.03 \\
\hline & Long & 0.66 & 0.04 & 0.57 & 0.03 & 0.52 & 0.04 & 0.48 & 0.03 & 0.52 & 0.03 & 0.5 & 0.04 \\
\hline & WLE & $-0.14^{*}$ & & -0.06 & & $0.10^{*}$ & & $0.11^{*}$ & & $0.15 *$ & & $0.18^{*}$ & \\
\hline Hulme et al. (2004) & Short & & & & & 0.66 & 0.04 & & & & & 0.67 & 0.03 \\
\hline \multirow[t]{2}{*}{ Exp. 1} & Long & & & & & 0.67 & 0.03 & & & & & 0.49 & 0.03 \\
\hline & WLE & & & & & -0.01 & & & & & & $0.27 *$ & \\
\hline \multirow[t]{3}{*}{ Exp. 2} & Short & & & & & 0.69 & 0.02 & & & & & 0.71 & 0.02 \\
\hline & Long & & & & & 0.68 & 0.02 & & & & & 0.59 & 0.02 \\
\hline & WLE & & & & & 0.02 & & & & & & $0.17 *$ & \\
\hline Present Study & Short & 0.66 & 0.03 & 0.64 & 0.03 & 0.64 & 0.03 & 0.60 & 0.04 & 0.67 & 0.04 & 0.64 & 0.03 \\
\hline \multirow[t]{2}{*}{ Exp 1} & Long & 0.76 & 0.04 & 0.65 & 0.04 & 0.57 & 0.04 & 0.59 & 0.04 & 0.58 & 0.04 & 0.5 & 0.04 \\
\hline & WLE & $-0.14 *$ & & -0.01 & & $0.10 *$ & & 0.02 & & $0.13^{*}$ & & $0.14^{*}$ & \\
\hline \multirow[t]{3}{*}{$\operatorname{Exp} 2$} & Short & 0.83 & 0.03 & 0.84 & 0.03 & 0.84 & 0.03 & 0.83 & 0.05 & 0.81 & 0.06 & 0.84 & 0.03 \\
\hline & Long & 0.85 & 0.05 & 0.87 & 0.04 & 0.83 & 0.03 & 0.81 & 0.04 & 0.75 & 0.04 & 0.74 & 0.04 \\
\hline & WLE & -0.02 & & -0.03 & & 0.01 & & 0.03 & & $0.08 *$ & & $0.12^{*}$ & \\
\hline \multirow[t]{3}{*}{ Exp 3} & Short & & & & & 0.71 & 0.04 & & & & & 0.75 & 0.05 \\
\hline & Long & & & & & 0.67 & 0.04 & & & & & 0.64 & 0.05 \\
\hline & WLE & & & & & $0.05^{*}$ & & & & & & $0.15^{*}$ & \\
\hline \multirow[t]{3}{*}{ Exp 4} & Short & 0.81 & 0.04 & 0.77 & 0.05 & 0.78 & 0.05 & 0.74 & 0.05 & 0.74 & 0.07 & 0.80 & 0.04 \\
\hline & Long & 0.87 & 0.05 & 0.78 & 0.06 & 0.76 & 0.04 & 0.69 & 0.05 & 0.68 & 0.05 & 0.66 & 0.05 \\
\hline & WLE & $-0.08 *$ & & -0.02 & & 0.03 & & $0.06^{*}$ & & $0.09 *$ & & $0.17^{*}$ & \\
\hline
\end{tabular}

Note-WLE is defined as (short - long)/short. An asterisk indicates a statistically significant difference by a two-tailed $t$ test (for Cowan et al., 2003) or post hoc LSD test (for all other data). 
tion condition. There were seven list types: pure short, pure long, and mixed lists containing one to five long items (and five to one short items). Within mixed lists, the exact placement of short and long items was randomly determined for each list and the order of conditions was also randomly determined. There were 20 trials of each type of list.

Procedure. Subjects were shown lists of six words, presented one at a time in the center of a computer screen for $1.5 \mathrm{sec}$ each, with no delay between words. After the final word disappeared, "Recall" appeared on the screen. The subjects were told that "Recall" was a cue for them to begin recalling the words by writing only the first three letters of each word in the appropriate lines on the response paper (the response paper had six lines next to each trial number). The subjects were told to write the words in the same order in which they were presented, starting with the first word. Recall was selfpaced. The subjects were tested one at a time, and the experimenter remained in the room to ensure that they followed the instructions.

\section{Results and Discussion}

The main data of interest are recall of short and long words in the pure lists in comparison with recall of short and long words when there were exactly three of each within the same list. In this and all subsequent experiments, alpha was set to .05 .

Experiment 1 replicated Cowan et al. (2003): More words were recalled in the pure short than in the pure long lists (.642 versus .553), the basic word length effect, but recall of short items in the key mixed lists was better than recall of long items (.635 versus .573$)$.

A two (list type: pure or mixed) $\times$ two (word length: short or long) ANOVA found no effect of list type $[F(1,19)<1]$. There was a reliable main effect of length $[F(1,19)=9.23$, $\left.M S_{\mathrm{e}}=0.012\right]$, with more short words recalled than long words. The interaction was not reliable $[F(1,19)<1]$. A series of post hoc LSD tests confirmed that there was a reliable word length effect in the pure lists, and also a reliable word length effect in the mixed lists. However, recall of the long items in the pure and mixed lists did not differ, and recall of the long items in the mixed lists was worse than recall of the short items in the pure short list. Results from the other conditions are shown in the fourth row of Table 1. Experiment 1 thus replicated Cowan et al. (2003): a word length effect obtained in both pure lists and mixed lists.

\section{EXPERIMENT 2}

Experiment 2 used the stimuli from Experiment 2 of Hulme et al. (2004) but the list types of Cowan et al. (2003).

\section{Method}

Subjects. Twenty different Purdue University undergraduates participated in exchange for credit in introductory psychology courses. All identified themselves as native speakers of American English.

Stimuli. The stimuli were 80 short (one-syllable) and 80 long (three- to five-syllable) words from LaPointe and Engle (1990) that were also used by Hulme et al. (2004).

Design. As in Experiment 1, there were seven list types: pure short, pure long, and mixed lists containing one to five long items (and five to one short items).

Procedure. The procedure was the same as in Experiment 1, except that the words were shown at a slightly faster rate of $1 \mathrm{sec}$ per item, and that subjects responded using strict serial reconstruction of order (as in Hulme et al., 2004). At the end of each list, the six words appeared on the screen in alphabetical order on clickable buttons. The subjects were asked to click on the buttons to reconstruct the order in which the words had been presented.

\section{Results and Discussion}

Despite the change in list type, the results replicated those of Hulme et al. (2004): More words were recalled in the pure short than in the pure long lists (.838 versus .745), replicating the basic word length effect, but recall of both the short items (.837) and the long items (.829) in the mixed lists was equivalent to recall of the pure short items.

A 2 (list type: pure or mixed) $\times 2$ (word length: short or long) ANOVA found a reliable main effect of list type $\left[F(1,19)=10.37, M S_{\mathrm{e}}=0.003\right]$, with better recall of mixed than of pure lists. There was also a reliable main effect of length $\left[F(1,19)=7.34, M S_{\mathrm{e}}=0.007\right]$, with more short words recalled than long words. The interaction was reliable $\left[F(1,19)=19.79, M S_{\mathrm{e}}=0.002\right]$, owing to worse recall of long items in the pure condition than in to the mixed condition. A series of post hoc LSD tests confirmed that there was a reliable word length effect in the pure lists, but no such effect in the mixed lists. Moreover, recall of short and long items in the mixed lists did not differ from recall of the short items in the pure lists. Recall of the long items in the pure lists differed from all other conditions.

\section{EXPERIMENT 3}

The results of Experiment 2 suggest that the type of list is not a critical factor behind the different results, as the Hulme et al. (2004) pattern is observable with both types of mixed lists. If the cause of the different results is due to the particular stimulus set used, we should be able to replicate the Cowan et al. (2003) pattern if we use their stimuli but the list types of Hulme et al.

\section{Method}

Subjects. Twenty different Purdue University undergraduates participated in exchange for credit in introductory psychology courses. All identified themselves as native speakers of American English.

Stimuli. The stimuli were the six short words and six long words from Experiment 1 that were also used by Cowan et al. (2003).

Design. The design was the same as that of Hulme et al. (2004) Experiment 2. There were three types of lists: pure (either just short or just long); alternating (either beginning with short or beginning with long); and random (.5 probability of a short item at each position). Every list contained six items, and the type of list presented on each trial was randomly determined. Subjects received 20 trials of each type of pure and alternating lists and 40 trials of random lists, resulting in a total of 120 trials.

Procedure. The procedure was analogous to that of Experiment 2.

\section{Results and Discussion}

The results replicated those reported by Cowan et al. (2003) and observed in Experiment 1: More words were recalled in the pure short than in the pure long lists $(.749$ vs. .640), the basic word length effect. Word length effects were also observed in the two types of mixed lists: short 
items were recalled better than long items in the alternating lists (.707 vs. .671) and in the random lists (.701 vs. $.666)$.

A 3 (list type: pure, mixed, or random) $\times 2$ (word length: short or long) ANOVA found no effect of list type $[F(2,38)<1]$. There was a reliable main effect of length $\left[F(1,19)=16.29, M S_{\mathrm{e}}=0.007\right]$, with more short words recalled than long words. The interaction was also reliable $\left[F(2,38)=6.257, M S_{\mathrm{e}}=0.003\right]$. A series of post hoc LSD tests confirmed that there was a reliable word length effect in the pure lists, and also a reliable word length effect in the alternating and in the random lists. Recall of items in mixed lists differed from recall of the short items from the pure lists.

\section{EXPERIMENT 4}

When the stimuli from Cowan et al. (2003) are used, their results are replicated regardless of the type of lists (Experiments 1 and 3). When the stimuli from Hulme et al. (2004) are used, their results are replicated regardless of the type of lists (Experiment 2 here and the two experiments in the original paper). Experiment 4 was designed to see which pattern of results would obtain when a new set of stimuli was used.

\section{Method}

Subjects. Twenty different Purdue University undergraduates participated in exchange for credit in introductory psychology courses. All identified themselves as native speakers of American English.

Stimuli. The stimuli were the 10 short words (crab, cheese, toad, torch, tent, ear, eye, ski, stool, sun) and 10 long words (caravan, celery, tomato, typewriter, telephone, elephant, envelope, motorbike, strawberry, submarine, screwdriver) used by Baddeley, Chincotta, Stafford, and Turk (2002).

Design and Procedure. The design and procedure were identical to those of Experiment 2.

\section{Results and Discussion}

The new set of stimuli produced the Hulme et al. (2004) pattern rather than the Cowan et al. (2003) pattern: More words were recalled in the pure short than in the pure long lists (.798 vs. .660), but recall of short and long items in the mixed lists did not differ (.785 vs. .775) and were equivalent to recall of short items from pure lists.

A 2 (list type: pure or mixed) $\times 2$ (word length: short or long) ANOVA found a reliable main effect of list type $\left[F(1,19)=15.21, M S_{\mathrm{e}}=0.003\right]$, with better recall of mixed than of pure lists. There was also a reliable main effect of length $\left[F(1,19)=46.73, M S_{\mathrm{e}}=0.002\right]$, with more short words recalled than long words. The interaction was reliable $\left[F(1,19)=32.57, M S_{\mathrm{e}}=0.002\right]$, owing to worse recall of long items in the pure condition. A series of post hoc LSD tests confirmed that there was a reliable word length effect in the pure lists, but no such effect in the mixed lists. Moreover, recall of short and long items in the mixed lists did not differ from recall of the short items in the pure list. Recall of the long items in the pure lists differed from all other conditions.

\section{GENERAL DISCUSSION}

Cowan et al. (2003) and Hulme et al. (2004) reported different results when subjects recalled equal numbers of short and long items from mixed lists. Moreover, neither pattern was predicted by the three major explanations of the word length effect. Their combined experiments, taken with the four reported here, suggest that the difference in empirical results may be attributed to the particular stimulus set used. ${ }^{1}$ The pattern of results reported by Cowan et al. (2003) is observed only when their particular stimuli are used, regardless of other experimental details (i.e., type of test, list type, etc.). In contrast, the pattern of results reported by Hulme et al. (2004) is observable with three different stimulus sets: The set of 6 short and 6 long items used in their Experiment 1, the set of 80 short and 80 long items used in their Experiment 2 and in Experiment 2 here, and the set of 10 short and 10 long items used in Experiment 4. These results parallel those of other studies that illustrate how critically important the choice of stimulus set is (e.g., Neath, Bireta, \& Surprenant, 2003).

We conclude, then, that the pattern of results reported by Hulme et al. (2004) is the more general: Not only do word length effects not occur in mixed lists, but recall of short and long items in mixed lists is equivalent to recall of short items in pure lists. None of the three models discussed above predict this pattern. Both the Brown and Hulme (1995) model and the feature model predict a word length effect in mixed lists, but no such effect is generally observed. Although the Burgess and Hitch (1999) model does correctly predict the lack of a word length effect in mixed lists, it does not predict the huge increase in the level of recall of the words in mixed lists.

A version of SIMPLE (Brown, Neath, \& Chater, 2002; Neath \& Brown, 2006) has been adapted by Hulme et al. (2004) to account for these results. Short words are assumed to differ from long items primarily in complexity (see also Caplan, Rochon, \& Waters, 1992; Service, 1998). In particular, short items are generally more distinctive than long words because of the less complex phonological representation. One can think of this in terms of the differences between short (simple) items being easier to apprehend than differences between long (complex) items. The basic word length effect is due to this differential distinctiveness. In mixed lists, short items lose no distinctiveness by being surrounded by long items. In contrast, long items gain distinctiveness in mixed lists in that now differences between them are easier to apprehend (i.e., compare the pure list of the long items hippopotamus, periodical, physiology, ... with the items in mixed list such as zinc, hippopotamus, scroll, ...). Hulme et al. report the complete details, as well as the results of a simulation. For the Cowan et al. (2003) stimuli, a further reduction of the distinctiveness of the longer items (due, for example, to their reduced imageability) within the SIMPLE framework would result in worse performance in the mixed lists.

Many memory results such as the bizarre imagery effect (McDaniel \& Einstein, 1986), the generation effect (Sla- 
mecka \& Katsaiti, 1987), and the word frequency effect (Watkins, LeCompte, \& Kim, 2000) can differ as a function of whether one uses a between- or within-subjects or a between- or within-lists design. Even the phonological similarity effect, better recall of dissimilar-sounding than similar-sounding items, is now thought to demonstrate differences depending on the type of list, pure or mixed (Farrel \& Lewandowsky, 2003). To this list, we can now add word length effects. Given such results, a model such as SIMPLE has the distinct advantage of positing that memory depends on the degree to which an item stands out from its immediate neighbors. As Hulme et al. (2004) demonstrate, such a conception does well in accounting for differences in the word length effect depending on whether an item is surrounded by short or long items.

\section{REFERENCES}

BADDELEY, A. [D.] (2000). The episodic buffer: A new component of working memory? Trends in Cognitive Sciences, 4, 417-423.

Baddeley, A. [D.], Chincotta, D., Stafford, L., \& Turk, D. (2002). Is the word length effect in STM entirely attributable to output delay? Evidence from serial recognition. Quarterly Journal of Experimental Psychology, 55A, 353-369.

Baddeley, A. D., Thomson, N., \& Buchanan, M. (1975). Word length and the structure of short-term memory. Journal of Verbal Learning \& Verbal Behavior, 14, 575-589.

Brown, G. D. A., \& Hulme, C. (1995). Modeling item length effects in memory span: No rehearsal needed? Journal of Memory \& Language, 34, 594-621.

Brown, G. D. A., Neath, I., \& Chater, N. (2002). A ratio model of scale-invariant memory and identification. Unpublished manuscript.

Burgess, N., \& Hiтch, G. (1999). Memory for serial order: A network model of the phonological loop and its timing. Psychological Review, 106, 551-581.

Caplan, D., Rochon, E., \& Waters, G. S. (1992). Articulatory and phonological determinants of word length effects in span tasks. Quarterly Journal of Experimental Psychology, 45A, 177-192.

Coltheart, M. (1981). The MRC psycholinguistic database. Quarterly Journal of Experimental Psychology, 33A, 497-505.

Cowan, N., Baddeley, A. D., Elliot, E. M., \& Norris, J. (2003). List composition and the word length effect in immediate recall: A comparison of localist and globalist assumptions. Psychonomic Bulletin \& Review, 10, 74-79.
FARREL, S., \& LEWANDOWSKY, S. (2003). Dissimilar items benefit from phonological similarity in serial recall. Journal of Experimental Psychology: Learning, Memory, \& Cognition, 29, 838-849.

Hulme, C., Surprenant, A. M., Bireta, T. J., Stuart, G., \& Neath, I. (2004). Abolishing the word-length effect. Journal of Experimental Psychology: Learning, Memory, \& Cognition, 30, 98-106.

LaPointe, L. B., \& Engle, R. W. (1990). Simple and complex word spans as measures of working memory capacity. Journal of Experimental Psychology: Learning, Memory, \& Cognition, 16, 1118-1133.

McDaniel, M. A., \& Einstein, G. O. (1986). Bizarre imagery as an effective memory aid: The importance of distinctiveness. Journal of Experimental Psychology: Learning, Memory, \& Cognition, 12, 54-65.

Neath, I., Bireta, T. J., \& Surprenant, A. M. (2003). The time-based word length effect and stimulus set specificity. Psychonomic Bulletin \& Review, 10, 430-434.

Neath, I., \& Brown, G. D. A. (2006). SIMPLE: Further applications of a local distinctiveness model of memory. In B. H. Ross (Ed.), The psychology of learning and motivation (Vol. 46, pp. 201-243). San Diego: Elsevier, Academic Press.

Neath, I., \& Nairne, J. S. (1995). Word-length effects in immediate memory: Overwriting trace decay theory. Psychonomic Bulletin \& Review, 2, 429-441.

PAGE, M. P. A., \& Norris, D. (1998). The primacy model: A new model of immediate serial recall. Psychological Review, 105, 761-781.

SERvice, E. (1998). The effect of word length on immediate serial recall depends on phonological complexity, not articulatory duration. Quarterly Journal of Experimental Psychology, 51 A, 283-304.

SlamecKa, N. J., \& Katsaiti, L. T. (1987). The generation effect as an artifact of selective displaced rehearsal. Journal of Memory \& Language, 26, 589-607.

Watkins, M. J., LeCompte, D. C., \& Kim, K. (2000). Role of study strategy in recall of mixed lists of common and rare words. Journal of Experimental Psychology: Learning, Memory, \& Cognition, 26, 239-245.

\section{NOTE}

1. One can readily create images for four out of the six short items (myth and trait being the exceptions) chosen by Cowan et al. (2003), but only one out of the six long items (undergraduate) is easily imageable. Consistent with this interpretation, the MRC database (Coltheart, 1981 ) shows that the short words are higher in concreteness (519 vs. 366) and imageability (501 vs. 465 ), although we note that the corpus does not contain trait, criminology, hypochondriac, or photosynthesis, so this suggestion is speculative.

(Manuscript received February 27, 2005; revision accepted for publication October 4, 2005.) 